\title{
Floral Scent and Nectar Sugar Composition of Temnadenia odorifera (Apocynoideae, Apocynaceae)
}

\author{
Rafael F. Silva, ${ }^{\oplus a, b}$ Natália A. B. Tinoco, ${ }^{a}$ Anna Tsukui, ${ }^{a}$ Cristiana Koschnitzke, ${ }^{c}$ \\ Inara C. Silva-Batista, ${ }^{c}$ Claudia M. Rezende ${ }^{a}$ and Humberto R. Bizzo ${ }^{\oplus *, b, d}$
}

\author{
aLaboratório de Análise de Aromas, Instituto de Química, Universidade Federal do Rio de Janeiro, \\ 21941-909 Rio de Janeiro-RJ, Brazil \\ ${ }^{b}$ Instituto de Pesquisas de Produtos Naturais, Universidade Federal do Rio de Janeiro, \\ 21941-902 Rio de Janeiro-RJ, Brazil \\ ${ }^{c}$ Departamento de Botânica, Museu Nacional, Universidade Federal do Rio de Janeiro, \\ 20940-040 Rio de Janeiro-RJ, Brazil \\ ${ }^{d}$ Embrapa Agroindústria de Alimentos, Av. das Américas, 29501, \\ 23020-470 Rio de Janeiro-RJ, Brazil
}

\begin{abstract}
Temnadenia odorifera is an endemic species from the Brazilian Atlantic Forest. This study was developed in order to identify the volatile compounds emitted by the living flowers and nectar, to evaluate the temporal pattern of scent emission, and the sugars composition of its nectar. Analyses of the flower scent by dynamic headspace in vivo, of nectar sugar composition and studies on floral biology were performed. Twenty-three volatile compounds were identified in the flowers scent. The total amount of odor emitted by flowers varied significantly throughout anthesis, ranging from $10232.7 \mathrm{ng} \mathrm{g}^{-1}$ (9 to $12 \mathrm{~h}$ ) to $620.2 \mathrm{ng} \mathrm{g}^{-1}$ (15 to $18 \mathrm{~h}$ ). 2-Phenylethanol and $(E)$-cinnamyl alcohol were the major compounds. Concentration ratio between disaccharides and the sum of hexoses ranged from 2.3 to 3.04 , which can be correlated to the physiological needs inherent to big bees, the most frequent insects in T. odorifera. Analysis of the chemical composition of T. odorifera flowers provided a broader understanding of the mechanisms responsible for plant-insect interactions.
\end{abstract}

Keywords: volatile organic compounds (VOCs), Euglossini, insect attraction, flower scent, dynamic headspace

\section{Introduction}

The reproductive success of plants that depend on biotic vectors for pollen flow is related to the efficiency of insect attraction. ${ }^{1}$ For pollination purposes, this involves the use of different olfactory and visual signals by the flower, which, in turn, offers resources as a reward for pollen transfer service. The relationship between plant and pollinator is generally mutually beneficial. While insects move pollen from one flower to another, promoting cross-pollination and thereby ensuring reproductive success, they receive floral rewards for their service. Services are rewarded through the provision of resources, such as nectar, pollen, floral oil and resin. ${ }^{2}$

Feed requirements of pollinating insects are responsible

*e-mail: humberto.bizzo@embrapa.br for most of their visits to flowers, and nectar is one of the main feeds provided by flowers. ${ }^{3}$ The chemical composition of floral nectar can vary, but in general, it is a sweet, aqueous secretion that consists mainly of sucrose, glucose and fructose carbohydrates, whose relative proportion determines the spectrum of consumers, as insects differ in nutrient requirements. ${ }^{2}$ Butterflies and bees, for example, prefer sucrose-rich nectar. ${ }^{4}$

Among the sensory signals used by flowers to promote their resources, visual aspects and fragrance are the most important characteristics. ${ }^{5}$ Historically, however, the visual signals emitted by flowers (e.g., color and morphology) have been rather overvalued compared with floral odor. ${ }^{6}$ Nevertheless, several studies have consolidated the understanding that complex plant-insect interactions in some systems are mainly mediated by a combination of visual and olfactory cues. ${ }^{7}$ However, floral odor often 
comprises the basis on which pollinators perform floral choices. ${ }^{8}$

Floral odor is constituted of a complex mixture of volatile organic compounds (VOCs), which can be released by different parts of the flower. ${ }^{8}$ Terpenes, derivatives of fatty acids and benzenoids are the most common classes of floral volatiles. The chemical diversity of volatiles in nature contributes to the versatility of this communication channel. ${ }^{9}$ Although some flowers apply very unusual compounds in the attraction of their pollinating insects, many plants emit common floral volatiles, which may turn the flowers potentially attractive to a wider range of insects. ${ }^{10}$

Both polylectic and oligolectic insects use odor for floral recognition. ${ }^{11}$ Different studies have shown that bees can detect pollen and nectar through odor, as well as detect recently visited flowers. ${ }^{12}$ In addition, some studies have shown that flowers concentrate fragrance release during pollinator visit peaks, a strategy used to increase attractiveness at the propitious time while saving energy. ${ }^{13}$

Thus, considering that the relationship between plant and insects is based on the emission of volatile compounds and the production of resources as a reward, ${ }^{14}$ the study of the floral odor chemistry and the sugar composition of nectar is fundamental for understanding the mechanisms that plants use to attract insects and, therefore, increase their reproductive success.

In the case of the Apocynaceae family, pollinating mechanisms are known to be complex and distinct among their subfamilies, in part because of the complexity and diversity of floral morphologies found among them. The diversity of floral fragrance patterns found within the Apocynaceae family is added to the complexity of the floral mechanisms. Since Knudsen and Gershenzon ${ }^{9}$ published their extensive and systematic compilation of floral odor, much progress has been made in relation to the knowledge of the floral odor of species of the family Apocynaceae. However, practically all the effort dedicated to the knowledge regarding the chemical composition of the floral odor of the species of this family has been directed to the subfamilies Asclepiadoideae and Rauvolfioideae. From all species of the Apocynaceae family that had their floral odor studied by headspace techniques, 98.2\% (55 species) belong to the subfamilies Asclepiadoideae and Rauvolfioideae. ${ }^{15,16}$

The pollinating mechanism of the species from the subfamily Apocynoideae is distinct from that of the Asclepiadoideae. ${ }^{17}$ For the subfamily Apocynoideae, however, the chemical composition of the floral headspace odor was reported for only one species so far. It is common, for example, to find species of the subfamily Asclepiadoideae with a slightly putrid, fetid, urine-like and pungent odor, whereas this fragrance profile is not commonly found in the subfamily Apocynoideae. ${ }^{18}$ Jürgens et al. ${ }^{16}$ studied more than 40 species of the subfamily Asclepiadoideae in the last 12 years, and stressed the importance of extending the studies on floral fragrance chemistry to other subfamilies in order to increase the knowledge about the chemical diversity of the floral odor of the Apocynaceae and their possible functions within the plant-pollinator relationship.

Temnadenia odorifera (Vell.) J.F.Morales (Apocynaceae) belongs to the subfamily Apocynoideae and is an endemic species of the Brazilian Atlantic Forest, occurring in restinga areas, ${ }^{19}$ an expression used to refer to low scrubs and forests that are established on sea-level sandy areas along the Brazilian coast. T. odorifera is a suitable system for the study of the floral odor and its possible relation to plant-insect interactions, since this species has a mechanism of pollination similar to other species of Apocynoideae. Another important reason to study this species is its endemism in the Atlantic Forest, a threatened biome and a biodiversity hotspot. ${ }^{20}$ The information gathered in this study may contribute to its preservation.

As a first step to understand the plant-insect interaction of T. odorifera and to expand our knowledge of the diversity of volatiles produced by Apocynaceae-Apocynoideae species, this study aimed to answer the following questions: (i) which volatile compounds are emitted by the living flowers and nectar?; (ii) what is the temporal pattern of scent emission and its relation to the visitation of insects?; and (iii) what is the sugar composition of the nectar?

To address these questions, we carried out a systematic analysis on the flower scent of T. odorifera using dynamic headspace in vivo, on the sugar composition of its nectar and on its floral biology.

\section{Experimental}

\section{Floral biology}

According to Brazilian law, collection and access were authorized by the Ministry of Environment (process IBAMA 02001.003166/2013-26). Material accessed after November 2015, in compliance with the law 13123/2015, was registered at SISGEN under the registry number A5AA808. The field work was carried out at two different sites: site 1, the municipality of Quissamã, state of Rio de Janeiro (2211'27'S, 41²5'33.5”W), with wild plants from a restinga vegetation area; and site 2 , the city of Rio de Janeiro, state of Rio de Janeiro (2254'29.3”S, $43^{\circ} 13$ '34.9'W), with cultivated plants from the Jardim Botânico of the Museu Nacional, Universidade Federal 
do Rio de Janeiro (Figure 1). The study was developed from November to June (2012 and 2013). Flowers were fixed in $70 \%$ ethanol, prepared from a $96 \%$ analytical grade ethanol (Tedia, São Paulo, Brazil) by dilution with distilled water for morphological analysis. Floral structures were measured using a Mitutoyo digital caliper (São Paulo, Brazil). Fresh flowers $(\mathrm{n}=22)$ were immersed in neutral red aqueous solution for $10 \mathrm{~min}$ and then washed in distilled water for the presence of osmophores. ${ }^{21}$ The sugar concentration in the nectar was measured with an Eclipse pocket refractometer (0-45\%; Turn Wells, UK). Focal observations of flowers were performed at site 1 , covering all the anthesis schedules for two days, to verify the quantity and types of floral visitors.

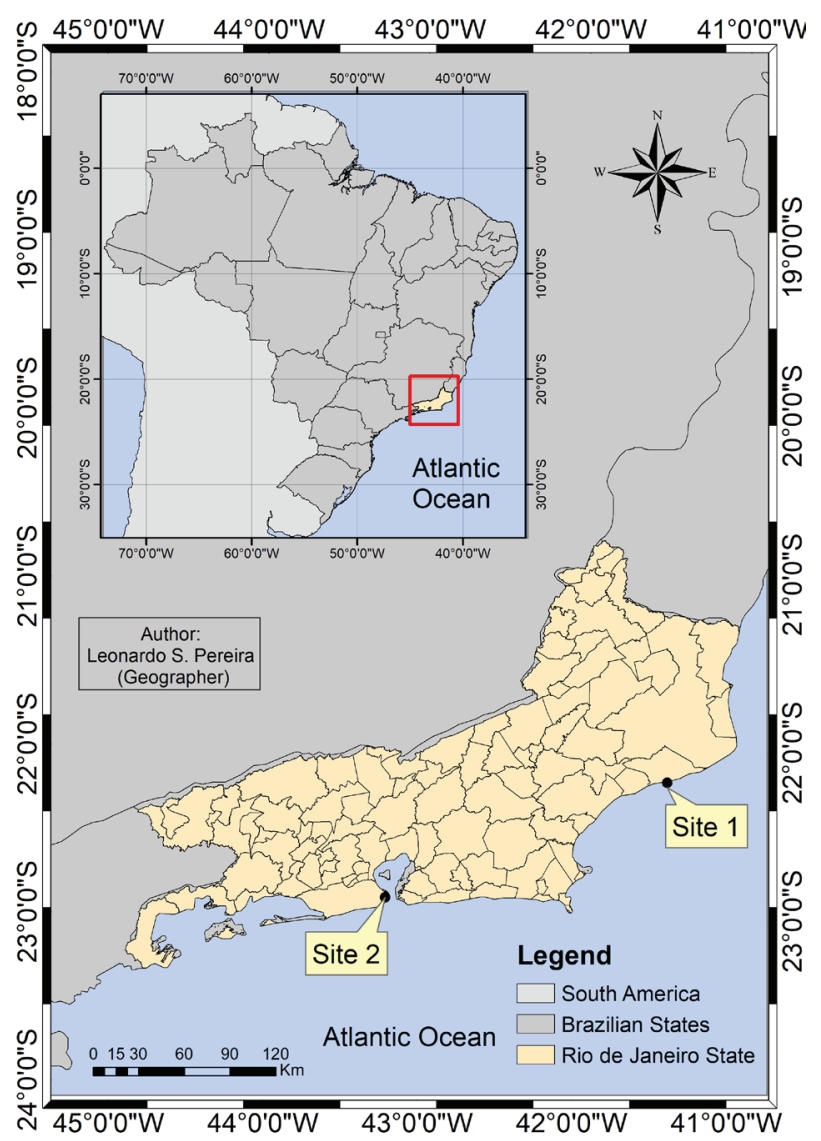

Figure 1. Map of Brazil and Rio de Janeiro State indicating sampling localities.

Volatile collection for analysis of the temporal variation of floral odor emission

Floral odor was collected using a dynamic headspace technique, based on the procedures of Raguso and Pellmyr ${ }^{22}$ and Kaiser. ${ }^{23}$

This part of the study was conducted at site 2 (Figure 1). Altogether, six individuals were sampled, one individual per day. The number of flowers in each day of extraction varied between one and three, according to the availability of open flowers. On the first day, the odor of two flowers of only one individual was sampled. On the second, third and fourth days, the odor of three flowers was sampled per day. For the fifth and sixth days, the odor of a single flower was sampled. For the extraction procedure, the entire inflorescence containing only flowers in anthesis was bagged in a polyethylene bag $\left(15 \times 25 \mathrm{~cm}^{2}\right)$ to isolate it from the external environment and minimize possible contamination. The volatiles that were emitted were captured in a homemade cartridge, consisting of a glass micro tube ( $2 \mathrm{~cm}$ long, $1 \mathrm{~mm}$ i.d.) that was open at both ends, containing $3 \mathrm{mg}$ of porous polymeric adsorbent (Porapak Q, 80-100 mesh; Sigma-Aldrich, Ontario, Canada), and was cleaned with $150 \mu \mathrm{L}$ of hexane prior to each extraction. Adsorbent was retained in the micro tubes by means of wool and glass beads.

The volatiles emitted by the plant were forced through the cartridge containing adsorbent by means of a vacuum pump connected to the system, with a flow of $200 \mathrm{~mL} \mathrm{~min}^{-1}$, and checked with a rotameter. To counterbalance the vacuum, a second positive flow pump was connected to the side opposite of the vacuum pump. Inlet air was filtered through an active charcoal cartridge $(30 \mathrm{mg}$ ) that was previously cleaned with $2 \mathrm{~mL}$ of hexane and dried for $30 \mathrm{~min}$ in a heated oven $\left(150{ }^{\circ} \mathrm{C}\right)$. To detect possible contaminants, control extractions were carried out in the same way as above, but using empty bags.

After each extraction, the adsorbent cartridge was eluted with $50 \mu \mathrm{L}$ of hexane (Absolv 99.5\%; Tedia, São Paulo, Brazil); then, $2 \mu \mathrm{L}$ of a $4 \mathrm{mg} \mathrm{mL}^{-1}$ solution of $n$-octadecane (99\%; Sigma-Aldrich, Milwaukee, USA) were added as an internal standard. The eluate was transferred to a micro ampoule, torch-sealed and stored under low temperature $\left(-16^{\circ} \mathrm{C}\right)$ until analysis.

The quantification of the volatiles was normalized by dry flower mass. Flowers were dried at $40{ }^{\circ} \mathrm{C}$ until constant mass. Pre-anthesis inflorescences were bagged, and the bags held until the beginning of the experiment. The chemical composition of the floral odor was evaluated from the extractions done in 2016 and 2017, both in the month of January.

To evaluate temporal variation of the volatile emission, the floral odor was sampled for $3 \mathrm{~h}$ in three periods of the day: 9-12 h, 12-15 h and 15-18 h. Sampling was repeated for six nonconsecutive days.

\section{Volatiles collection of senescent flowers}

The odor of flowers of $T$. odorifera in the senescence stage was also collected using the same procedure described 
above, for comparison with the volatile profile of the anthesis period. The flowers of three individuals were sampled on three nonconsecutive days. One individual per day was sampled. In each day, two flowers were sampled. The extraction was performed from $9 \mathrm{am}, 27 \mathrm{~h}$ after the beginning of anthesis, which occurred the morning of the previous day.

\section{Chemical analyses of floral odor collected}

A $2 \mu \mathrm{L}$ aliquot of each sample was injected in splitless mode into an Agilent 6890N gas chromatograph (GC; Palo Alto, USA) equipped with a flame ionization detector (FID) maintained at $280{ }^{\circ} \mathrm{C}$. Separation was achieved with an HP-5MS fused silica capillary column (Agilent; $5 \%$ phenyl methylpolysiloxane, $30 \mathrm{~m} \times 0.25 \mathrm{~mm} \times 0.25 \mu \mathrm{m})$, using hydrogen as carrier gas at a flow of $1 \mathrm{~mL} \mathrm{~min}{ }^{-1}$. Injector was kept at $250{ }^{\circ} \mathrm{C}$. Oven temperature was varied from $40{ }^{\circ} \mathrm{C}$ (for $5 \mathrm{~min}$ ) to $240{ }^{\circ} \mathrm{C}$ at a heating rate of $3{ }^{\circ} \mathrm{C} \mathrm{min}^{-1}$. The amount of each compound was calculated by the ratio of the internal standard absolute area to the area of each compound, corrected for the relative response factor (RRF), and expressed as the concentration in $\mathrm{ng} \mathrm{g}^{-1}$ of dry flower, according to the following formula:

$$
\mathrm{C}_{\mathrm{FVOC}}=\left[\left(\mathrm{PA}_{\mathrm{FVOC}} / \mathrm{PA}_{\text {standard }}\right) \times \mathrm{C}_{\text {standard }} \times \mathrm{RRF}\right] / \mathrm{W}_{\text {flower }}
$$

where $\mathrm{C}_{\mathrm{FVOC}}$ and $\mathrm{C}_{\text {standard }}$ are the concentrations of the target VOC and the internal standard, respectively; $\mathrm{PA}_{\mathrm{FVOC}}$ and $\mathrm{PA}_{\text {standard }}$ are the absolute peak areas of the dry flower VOC and the internal standard, respectively; and $\mathrm{W}_{\text {flower }}$ is the weight of the dried flower $(\mathrm{g})$.

The samples were also analyzed by GC with mass spectrometry (MS) detection, using an Agilent 6890N GC coupled to an Agilent 5973N mass detector and Agilent HP-5MS capillary column compound. Helium was used as carrier gas $\left(1 \mathrm{~mL} \mathrm{~min}^{-1}\right)$. The mass detector was operated in electronic ionization mode $(70 \mathrm{eV})$, with 3.15 scans per second and a mass range of 40 to $450 \mathrm{u}$. The transfer line was maintained at $260^{\circ} \mathrm{C}$, ion source at $230^{\circ} \mathrm{C}$ and analyzer at $150{ }^{\circ} \mathrm{C}$. The temperature program and the injection conditions were the same as those used in GC-FID.

\section{Calculation of the RRFs}

The RRFs were calculated for five different classes of volatiles that occur in the floral odor of T. odorifera. To calculate the RRF of a given chemical class, representative volatile substances (more than two, whenever possible) were diluted in hexane at four different concentrations $(0.04$, $0.08,0.16$ and $\left.0.4 \mathrm{mg} \mathrm{mL}^{-1}\right)$. An aliquot of $0.20 \mathrm{mg} \mathrm{mL}^{-1}$ of $n$-octadecane was added to all solutions. The obtained solutions were injected in a GC-FID, in triplicate. After the injections, calibration curves were constructed for each of the representative substance, based on the ratio of the internal standard and reference compound areas $v s$. the ratio between internal standard and reference compound concentrations. The formula used was

$\mathrm{RRF}=\mathrm{CA} /\left[\left(\mathrm{PA}_{\text {analyte }} / \mathrm{PA}_{\text {standard }}\right)\right] \times \mathrm{C}_{\text {standard }}$

where CA is the concentration of the standard compound, representing a chemical group (e.g., methyl salicylate and ethyl benzoate for aromatic esters); $\mathrm{PA}_{\text {analyte }}$ and $\mathrm{PA}_{\text {standard }}$ are the absolute peak areas of the analyte and the internal standard (n-octadecane), respectively; and $\mathrm{C}$ is the $n$-octadecane concentration. ${ }^{24}$

Representative compounds used for calculation of the response factors were limonene, $\alpha$-pinene and $\gamma$-terpinene (monoterpenes); linalool, carvone and $\alpha$-terpineol (oxygenated monoterpenes); (E)-caryophyllene and $\alpha$-humulene (sesquiterpenes); 3-octanone and acetophenone (ketones); (E)-cinnamaldehyde and benzaldehyde (aldehydes); methyl salicylate and ethyl benzoate (aromatic esters); and decanol and 3-methyl-2-decanol (aliphatic alcohols). All standards used were furnished by SigmaAldrich (purity > 98\%; Milwaukee, USA).

Nectar volatiles collection and chromatographic analysis (GC-MS)

To collect odor exclusively from nectar, the volatiles were extracted by solid-phase microextraction (SPME). The fiber used was composed of divinylbenzene, carboxen and polydimethylsiloxane (DVB/CAR/PDMS; 50/30 $\mu \mathrm{m}$; Supelco, Bellefonte, USA), and it was activated previously according to manufacturer's instructions.

For the extraction, $50 \mu \mathrm{L}$ of pure nectar from flowers from site 2 were transferred to a $1.5 \mathrm{~mL}$ vial and sealed with a poly(tetrafluoroethylene) (PTFE) septum cap. The nectar of nine individuals was collected in February (2017), by collecting from three individuals per day and from three flowers of each individual. The vial was heated to $40{ }^{\circ} \mathrm{C}$ for $40 \mathrm{~min}$. The SPME fiber was exposed to the headspace of the nectar for $30 \mathrm{~min}$; the vial was kept at $40{ }^{\circ} \mathrm{C}$, inserted into the injector of the chromatograph, and kept for $3 \mathrm{~min}$ at $250{ }^{\circ} \mathrm{C}$ (splitless) for the desorption and analysis of the volatiles extracted.

The analysis was performed in an Agilent 7890A GC that was equipped with an Agilent 5975C mass detector operated in selective ion monitoring mode (SIM). A $0.75 \mathrm{~mm}$ i.d. liner was used. An Agilent HP-5MS capillary column was used. Helium was used as carrier gas at a 


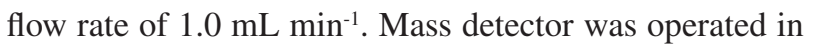
electronic ionization mode $(70 \mathrm{eV})$. The transfer line was maintained at $260{ }^{\circ} \mathrm{C}$, ion source at $230{ }^{\circ} \mathrm{C}$, and analyzer at $150{ }^{\circ} \mathrm{C}$. Oven temperature program was the same as that used to analyze the floral volatiles. The analyses were performed in triplicate.

\section{Identification of volatiles}

In all of the aforementioned cases, the identification of the volatile compounds was performed by comparison of both their mass spectra with those available in the Wiley Registry of Mass Spectral Data ${ }^{25}$ and their linear retention indices with published data. ${ }^{26}$ The linear retention indices were calculated according to Van Den Dool and $\mathrm{Kratz},{ }^{27}$ using the retention times of a homologous series of $n$-alkanes $\left(\mathrm{C}_{7}-\mathrm{C}_{26}\right)$ that were injected under the same conditions. In addition, the identification of some compounds present in the floral odor of $T$. odorifera was confirmed by the injection of authentic standards.

\section{Nectar collection}

Nectars from sites 1 and 2 (Figure 1) were collected in January 2017 and 2016, respectively. In both cases, they were collected with a $10 \mu \mathrm{L}$ syringe, transferred into a $1 \mathrm{~mL}$ vial with a $100 \mu \mathrm{L}$ volume reducer and stored at low temperature $\left(-16^{\circ} \mathrm{C}\right)$ until analysis. The flowers were bagged a day before the beginning of anthesis to avoid the consumption of nectar by floral visitors in forage.

\section{Analysis of nectar sugars}

Nectar sugars were analyzed by high-performance liquid chromatography (HPLC) in a Shimadzu HPLC LC-20AD 19777 system (Kyoto, Japan) with refractive index detector. Sample preparation for injection consisted of diluting an aliquot of nectar sample from individual flowers in mobile phase at a 1:9 ratio $(10 \mu \mathrm{L}$ of nectar in $90 \mu \mathrm{L}$ of mobile phase). The mobile phase was a $1 \mathrm{mM}$ solution of sulfuric acid (analytical grade; Vetec Química Fina, Rio de Janeiro, Brazil), prepared in ultrapure water (Milli-Q ${ }^{\circledR}$, Millipore Corporation, Burlington, USA). Sugar separation was achieved by injecting $5 \mu \mathrm{L}$ of sample solution into a Bio Rad (Hercules, USA) Aminex HPX-87H column $\left(150 \times 7.8 \mathrm{~mm}^{2}, 9 \mu \mathrm{m}\right)$ in isocratic mode. A flow of $0.7 \mathrm{~mL} \mathrm{~min}^{-1}$ of the mobile phase and $7 \mathrm{~min}$ of total run were sufficient for separation.

The method described above was validated for its accuracy, reproducibility, selectivity, linearity, limit of detection (LOD) and limit of quantification (LOQ). To verify selectivity, the matrix effect was investigated for sucrose, glucose and fructose by comparing their curves in aqueous solution and matrix (aqueous solution of nectar). After determining the matrix effect, the linearity was evaluated through the Grubb test, and homoscedasticity was evaluated by the Cochran test.

Calibration curves were constructed by injecting (in triplicate) aqueous solutions of the sugars at the concentrations of $1,5,10,20$ and $40 \mathrm{mg} \mathrm{mL}^{-1}$ for sucrose and $1,5,10,15$ and $20 \mathrm{mg} \mathrm{mL}^{-1}$ for the hexoses. Accuracy was determined by the recovery of sugars, and precision was determined by means of repeatability. LOQ and LOD were determined by injecting the sugars until the signal-to-noise ratio was equal to 3 and 10 , respectively. ${ }^{28}$

\section{Data analysis}

The statistical data analysis was performed using the Statistica 7.0 software, ${ }^{29}$ applying the analysis of variance (ANOVA) following Tukey's test for differences among averages with $5 \%$ level of significance.

\section{Results}

\section{Floral biology}

Temnadenia odorifera is a climbing vine that blooms from November to May, with flowering peak in January. The flowers (Figure $2 \mathrm{a}$ ) have a tubular corolla, with a diameter of $22.4 \pm 1.31 \mathrm{~mm}(18.0-24.5 \mathrm{~mm}, \mathrm{n}=35)$ and with the lobes facing to the right (Figure 2c) and perpendicular to the tube. At the base of the lobes, a platform of landing is formed that is, on average, $14.4 \pm 2.3 \mathrm{~mm}$ (10.6-19.4 mm; $\mathrm{n}=12$ ) in diameter. In this area, there is a star-shaped nectar guide whose tips protrude towards the base of the lobe and have a pink color, as observed in the inner part of the tube (Figure 2c). Epipetal stamens are inserted into the median internal region of the corolla tube and are cone-shaped, surrounding the apical part of the gynoecium (Figure $2 b$ ). Due to the positioning of the reproductive structures in the corolla tube, it is subdivided into inferior and superior regions. The inferior tube communicates only with the superior tube through five small spaces with diameters of $0.69 \pm 0.11 \mathrm{~mm}(0.38-0.9 \mathrm{~mm}, \mathrm{n}=40)$ between the fillets and the corolla. The corolla near the stamens and fillets presents several trichomes.

The anthesis begins at dawn and lasts $14 \mathrm{~h}$. At nightfall, the lobes move upwards, slightly wilted, and close the flower (Figure 2d), which remains in the inflorescence for one to two days. In the morning, the sweet odor of flowers is more intense than it is in the afternoon. Osmophores are 


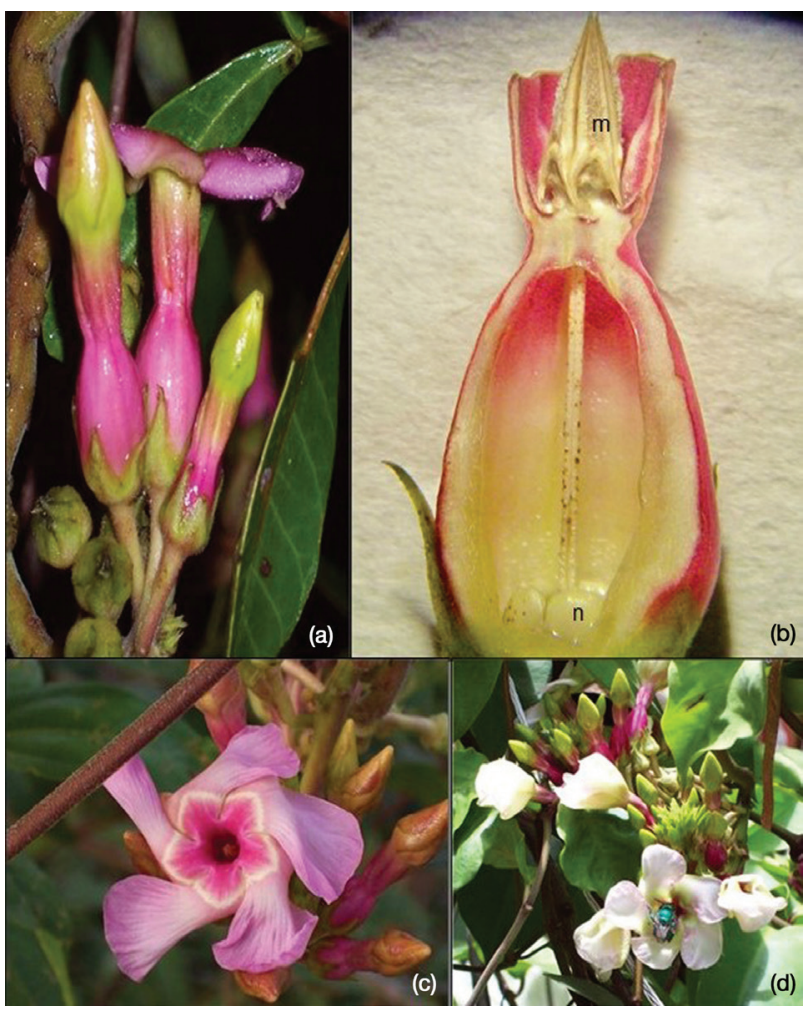

Figure 2. Flowers of Temnadenia odorifera. (a) Side view of corolla tube; (b) inferior tube of corolla longitudinally sectioned (n: nectary, $\mathrm{m}$ : anthers); (c) landing platform formed by the base of the lobes; and (d) inflorescence with flowers closed after anthesis and a Euglossini bee visiting the flower (photos by Cristiana Koschnitzke).

probably located on the inside of the corolla tube and on the landing platform, where the tissues are stained with neutral red. The nectary is a pentalocular disc located around the ovary, and the nectar produced accumulates at the base of the corolla tube. The overall sugar concentration of the nectar is $35 \pm 2.35 \%(29-39 \%, \mathrm{n}=120)$. The flowers were most visited by Euglossini bee (Figure 2d) males and females only for collecting nectar, by Lepidoptera and, eventually, by hummingbirds. The period of greatest visitation of bees and Lepidoptera was in the first $5 \mathrm{~h}$ of the anthesis, and it decreased greatly in the afternoon. The rare visits of hummingbirds were always at midday.

\section{Composition and odor temporal variation}

Twenty three volatile compounds, including monoterpenes (6), oxygenated monoterpenes (2), sesquiterpene (1), phenylpropanoids and benzenoids (11), were identified in the scent of $T$. odorifera flowers. The identified compounds are listed in Table 1 in order of elution. Regardless of the anthesis period, the floral fragrance was composed of few compounds, and only 11 of them (phenylpropanoids/ benzenoids) comprised between 66.2 and $83.0 \%$ of the floral fragrance. The floral odor profiles differed significantly between the different periods of anthesis investigated. Floral odor emission was higher during the period from 9 to $12 \mathrm{~h}$. In addition, 2-phenylethanol and $(E)$-cinnamyl alcohol were emitted at higher rates than other compounds at any other time of anthesis.

The total amount of odor emitted by flowers varied significantly $\left(\mathrm{F}_{2,12}=78.944, p<0.001\right)$ throughout anthesis. When the emission averages of the three investigated periods were compared, a significant difference (TukeyKramer test, $p<0.05$ ) was observed (Figure 3).

The analysis of the volatile chemical composition of $T$. odorifera in the senescence stage revealed that flowers continued to release volatiles, although at lower concentrations and lower diversity levels compared to those observed in anthesis (Table 1).

\section{Volatiles emitted by nectar}

Eight volatile compounds were detected in the nectar of T. odorifera flowers. The compounds are listed in Table 1. Nectar volatiles were present in low concentration at trace level, since they were not detected by MS in scan mode, and only in the more sensitive SIM mode. The compounds found in nectar were 3 terpenes ( $p$-cymene, limonene, and $\alpha$-copaene), two aromatic alcohols (benzyl alcohol and 2-phenylethanol), two aromatic esters (ethyl benzoate and methyl salicylate) and one aromatic aldehyde (benzene acetaldehyde).

\section{Composition and concentration of nectar sugars}

The data from method validation is available in the Supplementary Information (SI) section, Table S1. The composition and concentration of nectar carbohydrates are presented in Table 2. The nectar of $T$. odorifera contained sucrose, glucose and fructose, which are the three most common carbohydrates in floral nectar. ${ }^{30}$ Sucrose was the major compound in the nectar from both sites that were investigated, with a mean percentage concentration ranging from 68.3 to $75.0 \%$ (25.4 to $43.9 \mathrm{mg} \mathrm{mL}^{-1}$ ) of total carbohydrates (Table 2). The percentage concentration of the hexoses, glucose and fructose, ranged from 14.1 to 12.4 and 12.6 to $17.6 \%$, respectively (5.1 to 7.3 and 6.3 to $7.3 \mathrm{mg} \mathrm{mL}^{-1}$, respectively). The concentration ratio ( $r$ ) between the disaccharide and the sum of the hexoses ( $\mathrm{r}=$ sucrose / (glucose + fructose)) ranged from 2.3 to 3.04 (Table 2).

\section{Discussion}

The total amount of odor emitted by the flowers of T. odorifera decreases significantly throughout anthesis, 


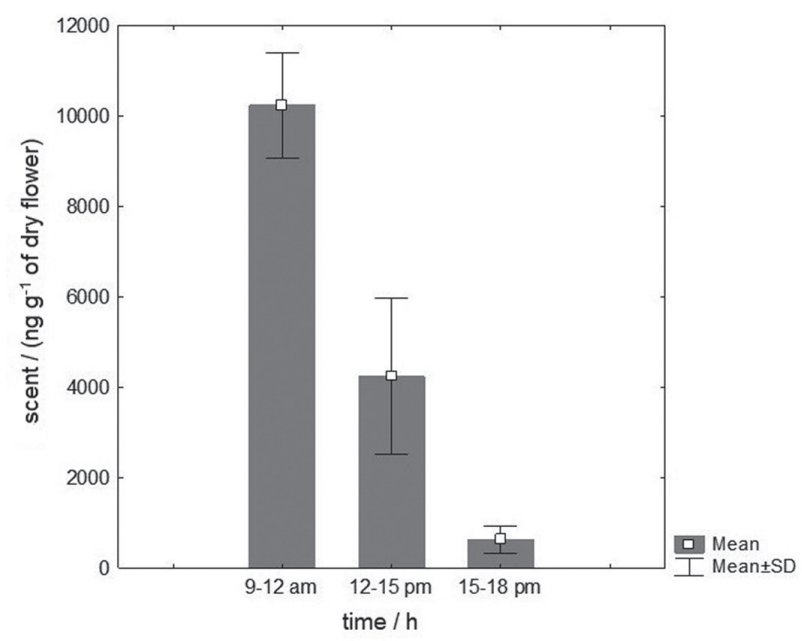

Figure 3. Comparison of the floral fragrance emission of $T$. odorifera in three periods of anthesis. with higher release in the morning when flowers are most visited by bees and Lepidoptera. Other authors who studied the plant-insect interaction in species that were pollinated preferentially by bees found similar results. According to Dressler, ${ }^{31}$ the Euglossine bees are more active in the morning, when they are usually in search of resources, such as nectar or fragrance. Thus, the convergence between greater odor emission and periods of greater activity for possible pollinators would be a strategy to concentrate their energy when the frequency of visitation to the flowers is high.

The floral odor of $T$. odorifera was dominated by terpenes, phenylpropanoids and benzenoids. These classes of compounds are common among plants pollinated by bees and butterflies. ${ }^{10}$

Studies related to scent collected from living flowers are very common for Orchidaceae, a family more studied in

Table 1. Emission rate of volatile compounds of T. odorifera flowers at different times of anthesis

\begin{tabular}{|c|c|c|c|c|c|c|c|c|}
\hline Peak & Compound / (ng g ${ }^{-1}$ of dry flower) & LRI $^{\mathrm{a}}$ & $\mathrm{LRI}^{\mathrm{b}}$ & 9 to $12 \mathrm{~h}^{\mathrm{c}}$ & 12 to $15 \mathrm{~h}^{\mathrm{c}}$ & 15 to $18 \mathrm{~h}^{\mathrm{c}}$ & Senescence $^{\mathrm{d}}$ & Nectar \\
\hline & total amount & - & - & 10232.7 & 5085.7 & 620.2 & - & - \\
\hline 1 & $\alpha$-pinene ${ }^{f}$ & 933 & 932 & $396.9 \pm 83.0$ & $189.5 \pm 116.0$ & $64.2 \pm 33.9$ & - & - \\
\hline 2 & benzaldehyde ${ }^{f}$ & 960 & 952 & $21.0 \pm 12.0$ & - & - & - & - \\
\hline 3 & $\beta$-pinene & 974 & 974 & $685.4 \pm 177.6$ & $178.5 \pm 126.5$ & - & - & - \\
\hline 4 & myrcene & 992 & 988 & $10.5 \pm 9.9$ & $7.6 \pm 9.3$ & - & - & - \\
\hline 5 & $n$-decane & 1002 & 1000 & $7.2 \pm 6.8$ & $18.2 \pm 19.5$ & - & - & - \\
\hline 6 & $p$-cymene ${ }^{\mathrm{f}}$ & 1024 & 1020 & $27.6 \pm 25.5$ & $29.5 \pm 45.5$ & - & $\mathrm{nq}$ & $\mathrm{nq}$ \\
\hline 7 & limonene $^{f}$ & 1026 & 1024 & $54.2 \pm 12.9$ & $167.6 \pm 243.8$ & $2.0 \pm 2.2$ & $\mathrm{nq}$ & nq \\
\hline 8 & benzyl alcohol ${ }^{\mathrm{f}}$ & 1035 & 1026 & $224.0 \pm 82.7$ & $97.7 \pm 78.5$ & $1.2 \pm 0.5$ & - & nq \\
\hline 9 & benzene acetaldehyde & 1042 & 1036 & $193.1 \pm 58.1$ & $233.1 \pm 383.0$ & $28.2 \pm 16.9$ & - & $\mathrm{nq}$ \\
\hline 10 & (E)- $\beta$-ocimene & 1049 & 1044 & $211.6 \pm 92.0$ & $97.5 \pm 141.7$ & $26.2 \pm 15.8$ & $\mathrm{nq}$ & - \\
\hline 11 & $\gamma$-terpinene & 1057 & 1054 & $\mathrm{nq}$ & $\mathrm{nq}$ & - & - & - \\
\hline 12 & acetophenone & 1065 & 1059 & $\mathrm{nq}$ & - & - & - & - \\
\hline 13 & linalool $^{\mathrm{f}}$ & 1096 & 1095 & $67.8 \pm 38.2$ & 99.0 & $9.5 \pm 9.9$ & - & - \\
\hline 14 & nonanal $^{\mathrm{f}}$ & 1100 & 1100 & $125.3 \pm 132.4$ & $163.7 \pm 196.2$ & $107.5 \pm 56.6$ & - & - \\
\hline 15 & 2-phenylethanol ${ }^{\mathrm{f}}$ & 1110 & 1106 & $5110.3 \pm 1194.9$ & $1836.7 \pm 502.5$ & $219.3 \pm 112.9$ & - & $\mathrm{nq}$ \\
\hline 16 & camphor & 1138 & 1141 & $20.1 \pm 12.9$ & $26.9 \pm 17.9$ & - & - & - \\
\hline 17 & (Z)-cinnamaldehyde & 1217 & 1217 & $19.9 \pm 24.4$ & $32.3 \pm 39.3$ & - & - & - \\
\hline 18 & 3-phenylpropanol & 1230 & 1231 & $\mathrm{nq}$ & $\mathrm{nq}$ & - & - & - \\
\hline 19 & (Z)-cinnamyl alcohol & 1261 & 1259 & $48.2 \pm 15.7$ & $10.3 \pm 6.4$ & - & - & - \\
\hline 20 & $(E)$-cinnamaldehyde ${ }^{f}$ & 1268 & 1267 & $118.1 \pm 78.4$ & $145.4 \pm 212.1$ & $162.0 \pm 73.2$ & - & - \\
\hline 21 & methyl 3-phenylpropanoate & 1274 & 1277 & $\mathrm{nq}$ & - & - & - & - \\
\hline 22 & indole & 1287 & 1290 & - & - & - & $\mathrm{nq}$ & - \\
\hline 23 & $(E)$-cinnamyl alcohol ${ }^{\mathrm{f}}$ & 1308 & 1303 & $2762.5 \pm 545.5$ & $1406.6 \pm 716.3$ & - & - & - \\
\hline 24 & $(E, E)$ - $\alpha$-farnesene & 1505 & 1505 & $128.9 \pm 57.6$ & $139.7 \pm 98.8$ & - & - & - \\
\hline 25 & ethyl benzoate & 1165 & 1169 & - & - & - & - & $\mathrm{nq}$ \\
\hline 26 & methyl salicylate & 1187 & 1190 & - & - & - & - & $\mathrm{nq}$ \\
\hline 27 & $\alpha$-copaene & 1371 & 1374 & - & - & - & $\mathrm{nq}$ & $\mathrm{nq}$ \\
\hline
\end{tabular}

a Experimental linear retention index; ${ }^{b}$ linear retention index from literature ${ }^{26}{ }^{\mathrm{c}}$ mean \pm standard deviation, $\mathrm{n}=6$; ${ }^{\mathrm{d}}$ the extraction was performed a day after the beginning of anthesis; ${ }^{t}$ the volatiles were extracted by (SPME) from pure nectar from flowers of site 2; fidentification confirmed with authentic standard. nq: not quantified. 
Table 2. Concentration and composition of $T$. odorifera nectar flowers

\begin{tabular}{|c|c|c|c|c|c|}
\hline & \multirow{2}{*}{$\mathrm{n}$} & \multicolumn{3}{|c|}{ Concentration / $\left(\mathrm{mg} \mathrm{mL}^{-1}\right)$} & \multirow{2}{*}{$\mathrm{S} /(\mathrm{G}+\mathrm{F})$ ratio } \\
\hline & & Sucrose & Glucose & Fructose & \\
\hline Site 1 & 5 & $43.9 \pm 4.1 \mathrm{a}$ & $7.3 \pm 0.85 c$ & $7.3 \pm 0.85 c$ & $3.04 \pm 0.36 \mathrm{~d}$ \\
\hline Site 2 & 11 & $25.4 \pm 6.8 b$ & $5.1 \pm 1.0 \mathrm{c}$ & $6.3 \pm 1.2 \mathrm{c}$ & $2.30 \pm 0.65 \mathrm{~d}$ \\
\hline
\end{tabular}

n: number of replicates; S: sucrose; G: glucose; F: fructose. Mean \pm standard deviation one-way ANOVA, $\mathrm{F}_{5,147}=360, p<0.05$. Different letters in the same row indicate statistically significant values through Tukey's test. Different letters in the same column indicate statistically significant values through Student's $t$-test, $P<0.05$.

relation to floral scent, according to Knudsen et al. ${ }^{32}$ However, comparatively, only a few studies have been carried out on species of the family Apocynaceae or on the subfamilies Asclepiadoideae and Periplocoideae. ${ }^{15,16,18,33}$ In some of these studies, bioassays, GC and electroantennography detection (EAD) were used to demonstrate that floral scent is decisive in attracting pollinators. ${ }^{33}$

The fragrance and chemical composition of orchid species are quite varied; however, some authors have noted that the floral odors of orchids pollinated by Euglossine bees have some common characteristics, such as a volatile profile with few compounds in high concentration. Furthermore, the compounds that are most commonly found in these orchids are the monoterpenes $p$-cymene, limonene, $\alpha$-pinene, myrcene, and 1,8-cineol, in addition to the benzenoids 2-phenylethanol, benzaldehyde, methyl salicylate, and benzyl benzoate. These characteristics are present in the floral odor of T. odorifera, which is also visited by Euglossine bees.

Only one study has been published to date on the odor of flowers from the subfamily Apocynoideae using in vivo sampling. Joulain ${ }^{34}$ worked with living flowers of Trachelospermum jasminoides, although the author did not perform any study relating the floral odor with flower chemical ecology.

Among the volatiles emitted by $T$. odorifera, several are known to trigger a positive behavioral response in Euglossine bees. ${ }^{35}$ Specifically, the compounds myrcene, limonene, linalool, methyl salicylate and $(E, E)$ - $\alpha$-farnesene are detected by the antennas of the Eulaema nigrita (Lepeletier), when subjected to EAD. ${ }^{36}$ This finding may suggest that $T$. odorifera plants have used at least some of these compounds to attract this species of bee. However, this hypothesis needs to be verified through behavioral bioassays.

In addition to bees, T. odorifera is visited by butterflies, and 2-phenylethanol is one of the most recurrent compound in plants pollinated by butterflies and an important marker, arousing an electrophysiological response in their antennas, such as in Inachis io, Aglais urticae and Gonepteryx rhamni. ${ }^{37}$ The compound 2-phenylethanol is present at a great proportion in T. odorifera floral odor in all periods of the investigated anthesis, which can be considered a sign of attraction for this type of insect.

However, although this compound is commonly associated with butterfly attraction, Kobayashi et al..$^{38}$ demonstrated the electrophysiological responses of Apis mellifera bee to this compound. Furthermore, 2-phenylethanol is very common in several species of the genus Gongora (Orchidaceae), which is recognized and pollinated by Euglossine bees. ${ }^{39}$ However, to the best of our knowledge, no studies were found to associate this compound with Euglossine bees through electrophysiological studies.

The second most abundant compound in the floral odor of T. odorifera, $(E)$-cinnamyl alcohol, also elicited electrophysiological responses in butterflies (Inachis io, Aglais urticae and Gonepteryx rhamni). ${ }^{37}$

Flowers of T. odorifera presented a sucrose-dominated nectar at both collection sites. In addition, the concentration of this disaccharide ranged from 25.4 to $43.9 \mathrm{mg} \mathrm{mL}^{-1}$ (one-way ANOVA, Tukey-Kramer test, $p<0.05$ ). The concentration of the hexoses, in contrast, did not show significant differences between the flowers at the sites that were investigated (one-way ANOVA, Tukey-Kramer test, $p>0.05$ ). Although the sucrose concentrations varied significantly between flowers at both sites investigated, the concentrations were very high, up from $68.3 \%$, compared to the sums of all carbohydrates present in the nectar.

There may be variability in the nectar composition in flowers of individuals of the same population and between different populations of the same species. This variability probably reflects the different photosynthetic activities of plants. As nectar sugars are derived directly or indirectly from photosynthesis, their composition may vary widely according to the plant exposure to light. ${ }^{40}$ Since T. odorifera plants from site 1 were much more exposed to sunlight than those at site 2 , it is possible that this variation in light exposure is the reason for the higher amount of sucrose in the nectar of the former.

The carbohydrate ratio $(\mathrm{r}=$ sucrose $/($ glucose + fructose $)$ ) has been correlated to the physiological needs inherent to 
each pollinator group..$^{30}$ Thus, sucrose-dominated nectars with $\mathrm{r}>1.00$ have been a constant in flowers pollinated by butterflies, hummingbirds and large bees, ${ }^{4}$ as is the case of T. odorifera species.

In addition to sugars, a broad spectrum of other minor metabolites, such as amino acids, lipids and VOCs, can often be found. The latter, however, are often neglected in nectar chemistry studies. Raguso, ${ }^{12}$ for example, found that among 127 studies devoted to the chemistry of nectar between 1993 and 2003, only one directly addressed the analysis of nectar odor. However, some studies have demonstrated the importance of considering the odor of nectars in some pollination contexts. ${ }^{41}$

In the present study, from the 8 volatile compounds detected in T. odorifera nectar, 5 were also found in floral odor, and 2 were found exclusively in the nectar (ethyl benzoate and methyl salicylate). These 2 substances are known for their attractiveness to bees ${ }^{35}$ and are even used as bait for capture in entomological studies. ${ }^{42}$ An explanation for the distinct presence of these substances in nectar could be to serve as a guide to direct their pollinators to nectar. As there are only small openings for the pollinator to introduce its tongue, or proboscide, into the lower tube of the corolla where the nectar is accumulated, the odor released by the nectar would indicate the right location for the pollinator to access the lower tube, functioning as a strategy of spatial differentiation. In addition, considering that nectar is an excellent medium for the proliferation of bacteria, the presence of $\alpha$-copaene in $T$. odorifera nectar may be associated with a possible strategy of inhibiting microbial growth, since some terpenes, among them sesquiterpenes, are known for their antimicrobial activity. ${ }^{43}$

Fragrance compounds in nectar can exhibit other ecological functions, such as antimicrobial agents, and may be used as an insect repellent for insects that are not effective pollinators. ${ }^{12}$ Thus, whereas limonene, linalool and aromatic esters were repellent to the hummingbird species Archilochus alexandri and Selasphorus rufus, aromatic alcohols were attractive. The aromatic esters methyl benzoate, ethyl benzoate and methyl salicylate had an attractive influence on the behavior of the Manduca sexta butterfly species. ${ }^{44}$

As already mentioned, only 2 substances were found exclusively in the nectar of $T$. odorifera, which may lead to a questioning about the origin of these volatiles. The simplest hypothesis, according to Raguso, ${ }^{12}$ which explains how the nectar becomes perfumed, states that volatiles released by floral tissues close to the nectar can be partially solubilized in the aqueous medium. For T. odorifera, this hypothesis is especially plausible, considering that the 5 volatile substances found in both nectar and floral odor are soluble in aqueous solution, as demonstrated by Weidenhamer et al. ${ }^{45}$

\section{Conclusions}

In conclusion, analysis of the chemical composition of the attractive and floral resources available in T. odorifera (volatiles and nectar, respectively) provided a broader understanding of the mechanisms responsible for plantinsect interactions. The ratio between disaccharide and hexoses of floral nectar, for example, shows a strong relationship with the prediction of its visiting insects. In addition, several volatiles found in $T$. odorifera flowers are common attractors to Euglossine bees. A considerable difference in the volatile profile of flowers in anthesis and senescence stages was observed, indicating a concentration of energetic effort of the species during anthesis. Methyl salicylate and ethyl benzoate were found only in nectar, suggesting they may act as guides to nectar. To the best of our knowledge, this is the first report on the chemistry of the scent emitted from living flowers and nectar of a species of the subfamily Apocynoideae (Apocynaceae). T. odorifera flowers also emitted high amounts of 2-phenylethanol and (E)-cinnamyl alcohol, which are known to be attractive to butterflies.

\section{Supplementary Information}

Supplementary data are available free of charge at http://jbcs.sbq.org.br as PDF file.

\section{Acknowledgments}

The authors thanks CNPq and FAPERJ for financial support. This study was financed in part by the Coordenação de Aperfeiçoamento de Pessoal de Nível Superior (CAPES, Brazil, Finance Code 001), with a scholarship for R. F. S. We thank Leonardo S. Pereira and the Laboratório de Geomorfologia Ambiental e Degradação dos Solos (UFRJ) for providing the map indicating sampling locations.

\section{References}

1. Majetic, C. J.; Raguso, R. A.; Ashman, T.; Funct. Ecol. 2009, 23, 480.

2. Agostini, K.; Lopes, A. V.; Machado, I. C. In Biologia da Polinização, 1ª ed.; Rech, A. R.; Agostini, K.; Oliveira, P. E.; Machado, I. C., eds.; Projeto Cultural: Rio de Janeiro, 2014, ch. 6 .

3. Heil, M.; Trends Plant Sci. 2011, 16, 191.

4. Baker, H. G.; Baker, I.; Isr. J. Bot. 1990, 39, 157. 
5. Schiestl, F. P.; Johnson, S. D.; Trends Ecol. Evol. 2013, $28,307$.

6. Raguso, R. A.; Entomol. Exp. Appl. 2008, 128, 196.

7. Burger, H.; Dötterl, S.; Ayasse, M.; Funct. Ecol. 2010, 24, 1234.

8. Raguso, R. A. In Advances in Insect Chemical Ecology, $1^{\text {st }}$ ed.; Cardé, R. T.; Millar, J. G., eds.; Cambridge University Press: Cambridge, 2004, ch. 5.

9. Knudsen, J. T.; Gershenzon, J. In Biology of Floral Scent, $1^{\text {st }}$ ed.; Dudareva, N.; Pichersky, E., eds.; CRC Press/Taylor and Francis: Boca Raton, 2006, ch. 5.

10. Filella, I.; Primante, C.; Llusià, J.; González, A. M. M.; Seco, R.; Farré-Armengol, G.; Rodrigo, A.; Bosch, J.; Peñuelas, J.; Sci. Rep. 2013, 3, 3434.

11. Burger, H.; Ayasse, M.; Dötterl, S.; Kreissl, S.; Galizia, C. G.; J. Comp. Physiol., A 2013, 199, 751.

12. Raguso, R. A.; Ecology 2004, 85, 1486.

13. Rodriguez-Saona, C.; Parra, L.; Quiroz, A.; Isaacs, R.; Ann. Bot. 2011, 107, 1377.

14. Parachnowitsch, A. L.; Manson, J. S.; Curr. Opin. Insect Sci. 2015, $8,41$.

15. Heiduk, A.; Brake, I.; Tschirnhaus, M. V.; Haenni, J. P.; Miller, R.; Hash, J.; Prieto-Benitez, S.; Jürgens, A.; Johnson, S. D.; Schulz, S.; Liede-Schumann, S.; Meve, U.; Dötterl, S.; Flora 2017, 232, 169.

16. Jürgens, A.; Dötterl, S.; Liede-Schumann, S.; Meve, U.; Biochem. Syst. Ecol. 2009, 36, 842.

17. Moré, M.; Sérsic, A. N.; Cocucci, A. A.; Ann. Mo. Bot. Gard. 2007, 94, 485.

18. Shuttleworth, A.; Biochem. Syst. Ecol. 2016, 66, 63.

19. http://floradobrasil.jbrj.gov.br/reflora/floradobrasil/FB4874, accessed in September 2018.

20. Myers, N.; Mittermeier, R. A.; Mittermeier, C. G.; Fonseca, G. A. B.; Kent, J.; Nature 2000, 403, 853.

21. Dobson, H. E. M.; Raguso, R. A.; Knudsen, J. T.; Ayasse, M. In Practical Pollination Biology; Dafni, A.; Kevan, P. G.; Husband, B. C., eds.; Enviroquest Ltd.: Cambridge, 2005, p. 13.

22. Raguso, R. A.; Pellmyr, O.; Oikos 1998, 81, 238.

23. Kaiser, R.; Chimia 2000, 54, 346.

24. Costa, R.; Zellner, B. A.; Crupi, M. L.; Fina, M. R.; Valentino, M. R.; Dugo, P.; Dugo, G.; Mondello, L.; Flavour Fragrance J. 2008, 23, 40 .

25. McLafferty, F. W.; Stauffer, D. B.; Wiley Registry of Mass Spectral Data, 6 ${ }^{\text {th }}$ ed.; Wiley Interscience: New York, 1994.
26. Adams, R. P.; Identification of Essential Oil Components by Gas Chromatography/Mass Spectrometry, $4^{\text {th }}$ ed.; Allured: Carol Stream, 2007.

27. Van Den Dool, H.; Kratz, P. D.; J. Chromatogr. A 1963, 11, 463.

28. Tinoco, N. A. B.; Uekane, T. M.; Tsukui, A.; Aguiar, P. F.; Teixeira, C. M. L. L.; Rezende, C. M.; J. Braz. Chem. Soc. 2016, 27, 1452.

29. StatSoft, Inc.; Statistica 7.0; StatSoft, Inc., Tulsa, OK, USA, 2004.

30. Lotz, C. N.; Schondube, J. E.; Biotropica 2006, 38, 3.

31. Dressler, R. L.; Annu. Rev. Ecol. Syst. 1982, 13, 373.

32. Knudsen, J. T.; Eriksson, R.; Gershenzon, J.; Ståhl, B.; Bot. Rev. 2006, 72, 1.

33. Zito, P.; Dötterl, S.; Sajeva, M.; J. Chem. Ecol. 2015, 41, 340.

34. Joulain, D.; Flavour Fragrance J. 1987, 2, 149.

35. Dötterl, S.; Vereecken, N. J.; Can. J. Zool. 2010, 88, 668.

36. Milet-Pinheiro, P.; Navarro, D. M. A. F.; Dotterl, S.; Carvalho, A. T.; Pinto, C. E.; Ayasse, M.; Schlindwein, C.; Phytochemistry 2015, 116, 149.

37. Andersson, S.; Chemoecology 2003, 13, 13.

38. Kobayashi, K.; Arai, M.; Tanaka, A.; Matsuyama, S.; Honda, H.; Ohsawa, R.; Breed. Sci. 2012, 62, 293.

39. Hetherington-Rauth, M. C.; Ramírez, S. R.; Ann. Bot. 2016, $118,135$.

40. Pacini, E.; Nepi, M.; Vesprini, J.; Plant Syst. Evol. 2003, 238, 7.

41. Parachnowitsch, A. L.; Burdon, R. C. F.; Raguso, R. A.; Kessler, A.; Plant Signaling Behav. 2013, 8, 137.

42. Ferreira, M. G.; Pinho, O. C.; Balestieri, J. B. P.; Faccenda, O.; Neotrop. Entomol. 2011, 40, 639.

43. Dötterl, S.; Jürgens, A.; Plant Syst. Evol. 2005, 255, 99; Bubán, T.; Orosz-Kovács, Zs.; Farkas, Á.; Plant Syst. Evol. 2003, 238, 183; Tholl, D.; Chen, F.; Petri, J.; Gershenzon, J.; Pichersky, E.; Plant J. 2005, 42, 757; Barrero, A. F.; Moral, J. F. Q.; Lara, A.; Herrador, M. M.; Planta Med. 2005, 71, 67.

44. Raguso, R. A.; Willis, M. A.; Anim. Behav. 2005, 69, 407.

45. Weidenhamer, J. D.; Macias, F. A.; Fischer, N. H.; Williamson, B.; J. Chem. Ecol. 1993, 19, 1799.

Submitted: June 7, 2018 Published online: September 24, 2018 